\title{
Reflections on running online expert advisory groups with young people with lived experience of depression
}

Juliette Westbrook ${ }^{1}$, Sophie M. Allan ${ }^{2,3}$, Brioney Gee ${ }^{2}$, Faith Orchard ${ }^{4 *}$

${ }^{1}$ Department of Psychology, University of Bath, Bath, BA2 7AY, ORCID: 0000-0003-1400953

${ }^{2}$ Norfolk and Suffolk NHS Foundation Trust, Hellesdon Hospital, Drayton High Road, Norwich, NR6, ORCID: 0000-0002-3601-0580; 0000-0003-0781-7753

${ }^{3}$ University of East Anglia, Norwich Research Park, Norwich, NR4 7TJ

${ }^{4}$ School of Psychology, University of Sussex, Falmer, East Sussex, BN1 9QH

* corresponding author F.Orchard@sussex.ac.uk; ORCID: 0000-0002-5324-5007

Declarations and conflicts of interest: The authors declare no conflicts of interest with this work Statement of ethics: As a reflective piece on involvement work, ethical approval was not required.

Consent for publication: $\mathrm{n} / \mathrm{a}$

Originality of article statement: this article has not been submitted for publication anywhere else, nor has been published in any form prior to submission to Research for All. The authors agree that the submission is original. 


\begin{abstract}
Service user involvement is fundamental to healthcare research, including knowledge transfer, advising on study protocols and the development of interventions. However, to date, service user involvement within child and adolescent mental health research is still uncommon and there is limited focus on best practice within the literature. Furthermore, consultations and advisory groups have traditionally been held face-to-face; however, the COVID-19 pandemic has accelerated a shift towards online research involvement as an alternative. This paper will examine our experience of conducting online expert advisory groups with young people (aged 14-24) with lived experience of depression and describe challenges and adaptations that need to be considered in order to make the events safe and accessible. Based on our own reflections of the process and feedback from young people taking part, we highlight the grouping of young people, facilitating pre-session nerves, intergroup communication and accessibility of online engagement. Young peoples' reflections on the value of the advisory groups are also discussed. We conclude by offering suggestions, based on our reflections, for future online research consultations.
\end{abstract}

\title{
Key words:
}

Consultation; Depression; Online; PPI; Self-Evaluation; Service user involvement; View of Self; Young people; YPAG

\section{Key Messages}

- We found that online platforms are a viable alternative to face-to-face research involvement consultations

- Attention needs to be given to the information that is shared with young people prior to the session, as well as facilitation of the session and group size 
- Researchers must be aware of the physical space young people have to undertake online $\underline{\text { consultations and ensure that it is safe for them to join }}$

\section{Background}

Involving young people (YP) in decisions about their health care is important for legal and moral reasons. YP's right to involvement in healthcare decision making has been enshrined in international law for over 30 years (United Nations, 1989). Service user involvement in clinical research is similarly crucial and has been shown to improve research quality and recruitment (Boivin et al 2018; Crocker et al., 2018). Furthermore, research has shown that young people want to contribute and be involved with the research process (Mawn et al, 2015).

Research involvement refers to members of the public, often those with relevant lived experience, contributing to the research. Despite the acknowledged value of involving people with lived experience in mental health research (Wellcome Trust's 'Mental Health Priority Area'; Medical Research Council's 'Developing Minds'), service user involvement is still uncommon and often tokenistic (Banfield et al., 2018; Dewa et al, 2020). For instance, fewer than $1 \%$ of empirical child and adolescent health studies published in 2019 reported using youth advice (Sellars et al, 2020).

Traditionally, research involvement has been conducted face-to-face. However, the COVID-19 pandemic accelerated the move towards use of online video conferencing software to facilitate research activities (Hewitt et al, 2020). Carrying out research activities online offers some potential advantages, such as reduced travel time (Almathami et al, 2020), increased cost- 
effectiveness (Fielding et al, 2008) and better accessibility (Arichibald et al, 2019). However, online interfaces can also create new challenges for researchers, including developing rapport (Webber et al, 2020) and communicating effectively with YP (Dandachi et al, 2020). Given the relative novelty of the use of video conferencing for research activities, these barriers and possible solutions have gained little attention to-date.

In this paper, we will reflect on our experiences of running online research advisory activities with YP (aged 14-24) with lived experience of depression, triangulating these reflections with feedback from the YP. This work was conducted as part of an analysis of 'Active Ingredients' of interventions for adolescent anxiety and depression commissioned by the Wellcome Trust. The topic of our advisory events was self-evaluation. In these events, we examined self-evaluation both as 1) a characteristic of the depression, and 2) an active ingredient in treatment for adolescent depression. To aid comprehension, we used the term 'view of self' instead of 'self-evaluation' during all youth involvement activities.

The focus of this paper will be our reflections of running the young person advisory events. We will reflect on the challenges and benefits of online delivery and suggest ideas for those involved in organising future online research advisory activities.

\section{Process}

YP aged 14-24 years with lived experience of depression were invited to take part in advisory events through existing youth involvement groups, including those run by NHS trusts, county councils and national charities. Twenty-five YP joined an event. Seven events were held: three attended by between five and nine YP, and four one-to-one meetings. Three 
facilitators were present at the group meetings; the one-to-one meetings were carried out with a single facilitator. Advisory events were held using the online platform 'Zoom' (www.zoom.us) - as used in online group-based psychiatric interventions (Childs et al, 2020). Events ran in the afternoon and lasted approximately one hour. YP were compensated for their time with online shopping vouchers (rates chosen in accordance with the National Institute for Health Research INVOLVE guidelines (INVOLVE, 2016)).

The events started with a brief discussion on a 'group agreement', which included confidentiality and respecting each other. A brief icebreaker activity involving discussing and ranking definitions of 'view of self' was then undertaken to begin to engage YP in the topic. Following this, there were three group discussions:

1. Do you think YP view themselves differently when they are depressed? If so, in what kind of ways?

2. Do you think how YP view themselves changes as they recover from depression?

3. Should how YP view themselves be talked about in therapy?

Questions were written in the chat function of the platform to help keep the discussions focussed. Discussions were carried out either as a whole group, or in breakout rooms when there were more than five YP on the call. Following the events, we asked YP about their experience of being involved

Discussions were audio recorded and recordings stored locally. Recordings were transcribed verbatim and analysed thematically based on Braun and Clarke's (2006) six-step approach. 
Findings were summarised and sent by e-mail. YP were invited to give anonymous feedback via an online survey regarding whether the results accurately reflected their discussions, and about their experiences of the advisory activities (Overall, how was your experience of participating in the project? What was good? Would you have changed anything?). 


\section{Reflections}

'It's good but there's room for improvement. I think we have made progress though'

The teams' reflections, quotes from YP in the event transcripts, and YP's feedback from the anonymous survey were combined and organised into key reflection topics. Verbatim quotes from the YP who were involved in the consultation activities were selected to illustrate the reflections discussed.

\section{Reflection 1: Individual versus group events}

'I don't really like discussing depression with others because I feel like it could be a bit competitive or triggering or I may feel like other people have it worse'

In accordance with YP's preferences, some of advisory activities were completed oneto-one. The quotation above demonstrates that some YP do not feel comfortable discussing their experience of depression in groups. Nevertheless, other YP really valued the group approach: 'I felt accepted and included as so many people had the same ideas as myself'. This highlights the importance of adapting the advisory events to suit individual needs and preferences.

We found that both group and one-to-one events had advantages and disadvantages. Group discussions were helpful to gain consensus, and stimulate discussion about topics, for example the definitions of self-evaluation. However, we found that not all YP discussed their experiences during the groups, which was something that a one-to-one discussion facilitated. 


\section{Reflection 2: Working with wide age ranges}

'I was really nervous at first because there was meant to be three or four other people that could have been younger than me'

Our events involved participants across a relatively wide age-range (14-24 years). As adolescence is a period of rapid growth and development (Christie and Viner, 2005), the discrepancy in life experiences between those of different ages could be a particular concern. The discrepancy in age was identified as a worry for some participants, 'I've not really had to speak about my mental space in front of anyone younger, am I going to end of saying something that's a bit too much?'.

In larger groups where the majority of participants did not know each other prior to the session, we split the groups into breakout rooms based on age. We observed that groups split by age were more open and appeared to relate to their fellow group members more easily. We found that informing sub-group members that we had placed participants in groups according to age seemed to increase trust and openness among group members.

\section{Reflection 3: Accommodating pre-session nerves}

'Am I going to say enough, am I just going to sit there awkwardly'

YP told us 'these kind of calls can be a bit intimidating at times' and they highlighted how they may struggle to engage or talk via online platforms: 'I've only just started to be able 
to talk out loud on Zoom because I have anxiety and it's actually good, better than I expected'. During feedback, some YP expressed that they felt nervous prior to attending: 'Just the fear of the unknown, and not knowing exactly how it was going to go down' and 'not knowing what we talk about and who was doing it because we don't really know each other'.

We asked the YP how we could reduce anxieties associated with attending the session. One participant commented, 'the ice breaker, as it was a bit awkward'. YP gave suggestions for additional steps that we could have taken to reduce pre-session nerves, such as having a more informal and relaxed icebreaker not related to the depression topic, sending example questions, or providing more information about the event in advance

Letting YP know in advance that they would be given the option to have their cameras turned off, and could use the chat function to communicate their ideas as an alternative to verbal communication, may also have served to reduce pre-session anxieties.

\section{Reflection 4: Intergroup communication and dynamics}

I felt listened to and it was amazing to be able to speak to people who understand how Ifeel'

The YP were respectful and encouraging during events, agreeing with and supporting each other's points, 'Someone said something in the chat and I think it's a really good point', and 'yeah, I think totally in agreement with everything you just said [young person's name]'. The supportive dynamic and forthcoming nature of the participants was something that we had not necessarily anticipated, but was evidence of rapport being built between participants. 
Interestingly, we also observed that YP appeared to bring their own self-evaluations and self-doubts into the 'room' with them, 'that was very long winded, like even now I want to keep apologising for talking' (a fellow young person then said, 'no, don't worry about it'). To ensure that activities are safe, contained and a positive experience for YP, researchers carrying out advisory activities of this nature with YP should be aware of the possible impact of personal insecurities.

In order to help build rapport and trust between participants, we kept YP and facilitators in the same breakout room for each discussion, 'If you keep changing too much people might get too agitated'. We observed that, as the event progressed, participants engaged in increasingly in-depth discussions and disclosed more information. The rapport and trust built up by maintaining consistency in the group and with the facilitators could have contributed to this.

\section{Reflection 5: Managing the possibility of distress}

'You were very friendly, you asked me nice questions, I felt really safe'

One important consideration prior to running the online events was the procedure to follow should a young person become distressed during or after the event. We were alert to the possibility of evoking distress, given that we were asking YP to reflect on a sensitive and personal topic. We ensured that we had the contact details of all participation leads who had put us in touch with the YP, and that they agreed to be a point of contact should any risk or 
safeguarding issues arise. In one case, a participation worker joined the YP on the call. Further, one of the facilitators in the events was a clinician with previous experience of running youth advisory groups.

Facilitators informed the YP that they would stay on the call for a period after the event had ended, and YP were encouraged to stay and talk if they felt upset or distressed. When asked, none of the YP reported that they felt distressed after the call. However, it is important that researchers are mindful of the potential for involvement activities with discussion of sensitive issues to cause distress and to have appropriate management plans in place. This is particularly important when conducting advisory groups online, where distress may be more difficult to detect.

\section{Reflection 6: Making consultation activities inclusive and accessible for YP}

I've had so many cups of tea waiting, I've been to Costa, Starbucks, Maccies [McDonald's] trying to find Wifi.'

Working with YP on sensitive topics via online platforms is not straightforward, and requires researchers to be flexible, accommodating and understanding. Researchers should not make the assumption that YP have appropriate physical spaces in which to attend online events. Their environments are not always quiet and there are often other people around, such as siblings or parents, '['brothers name'] shhhh please, sorry my brother is here'. Furthermore, some YP did not have access to stable internet connections at home and thus were calling from public places. We learnt the importance of being attentive to this, to ensure that YP are safe to attend, and feel comfortable taking part in online advisory events of this nature. 
Guidance documents detailing how to download and use the online platform were sent to YP in advance. We had two discussion facilitators and an additional member of the research team present to co-ordinate breakout rooms and to deal with any technological issues. We also sent individual messages to participants via the chat function if they missed part of the discussion, to catch them up without disrupting event progress, 'I'm not going to lie, I didn't hear anything you just said'. Additional facilitators were also able to manage ad hoc issues such as recording, reminding participants to unmute, and being prepared to step in if other facilitators lost internet connection.

\section{Reflection 7: YP's reflections on the value of consultation activity}

'Participating was amazing. I felt listened to and it was amazing to be able to speak to people who understand how I feel'

The vast majority of feedback from YP, both during the event and in the anonymous feedback questionnaire, was positive. Individuals reported that they appreciated the opportunity to engage in discussions on this topic, 'It was a pleasure to take part in it! I'm grateful to have had the opportunity to speak about something so important!', with people who had similar experiences to them 'I really did enjoy the meeting and talking to you guys made me feel a lot better and especially as [there] were other YP who felt the same as me, made me feel less alone so genuinely thank you so much!'.

YP showed a passion for making change and helping others, 'I went though it myself so I know a lot about it and I understand how it all works or how it should work, it's very important 
for me to help to change it for YP' and 'I've been through a lot, and I'd love to tell my story so [others] don't feel like they are alone'. They enjoyed the opportunity to be able to voice their opinions and experiences 'It's is very [important] for YP to have a voice to speak out', and to feel listened to 'I enjoyed participating in this project as I felt listened to and understood'.

The events highlighted a desire for change, specifically regarding mental health stigma and increasing education on mental health conditions. 'I think even though society is becoming better I guess, there's still a lot of stigma around mental health in general, because of lack of education, lack of empathy'. The YP highlighted that this stigma could contribute to worsening mental health, 'it makes you feel more rubbish about yourself' and behaviours such as not being honest with others about how they were feeling.

\section{Key recommendations for future practice based on our reflections}

1. Consider using breakout rooms to split groups with five or more YP into smaller discussion groups. Where groups need to be divided, consider splitting based on age.

2. Be open to facilitating one-to-one meetings for YP who do not feel comfortable sharing their experiences in group discussions.

3. Provide YP with information prior to the event about the nature of the activity, for example, 'you will be with four other people of a similar age to you, all with experience of depression'.

4. Give YP the option to use the chat function to type their responses if they feel more comfortable doing this; let them know in advance that this will be an option. 
5. Be aware that YP may not have a quiet private space from which to join online events. Consider practicalities such as encouraging participants to mute their microphones when not speaking.

6. If possible, have an additional facilitator responsible for resolving any issues with technology, organising breakout rooms, and catching YP up if they join the event late.

\section{Conclusion}

In conclusion, it is feasible to conduct online research advisory events with YP who have lived experience of depression. For some YP this approach may have advantages over inperson involvement activities, however challenges that may be encountered include group sizes, building trust and technical considerations. We found that YP valued the opportunity to engage in online advisory activities. The insights gained from YP with lived experience were invaluable, providing us with a sophisticated understanding of their experiences. We would argue that there is extensive value to embedding insights from YP with lived experience within mental health research, and hope that this becomes more common in future research.

\section{Funding}

This work was funded by a Wellcome Trust Mental Health Priority Area 'Active Ingredients' commission awarded to FO at the University of Reading. The views expressed in this publication are those of the authors and do not necessarily reflect those of the Wellcome Trust.

\section{Acknowledgements}


We would like to thank all of our YP, researchers and clinicians for taking the time to participate in in our expert advisory events. We would also like to think the young people's participation leads for their support throughout the consultations.

We would also like to acknowledge the contributions of Dr Laura Pass and Dr Tim Clarke who were co-investigators on the self-evaluation 'Active Ingredients' project.

\section{Notes on the contributors}

Juliette Westbrook is a postgraduate student at the University of Bath and worked as a research assistant on this Wellcome Trust Active Ingredients project. Her research interests include adolescent mental health, development and lived experience involvement.

Sophie M. Allan is a Clinical Psychologist in the West Norfolk Early Intervention in Psychosis Service. She trained at the University of East Anglia and qualified in September 2020. Her interests lie in service user involvement, co-production and first episode psychosis.

Brioney Gee is a post-doctoral researcher currently working as the Child, Family and YP's Research Development Lead for Norfolk and Suffolk NHS Foundation Trust. Her research focuses on increasing access to effective early interventions for YP experiencing mental health difficulties.

Faith Orchard is a Lecturer in Psychology at the University of Sussex. She conducts research into child and adolescent mental health, and has focused on understanding the causal and maintaining factors involved in adolescent depression. She is also exploring the development of novel treatments for the prevention and early intervention of adolescent depressive symptoms. 


\section{References}

Almathami, H. K. Y., Win, K. T., \& Vlahu-Gjorgievska, E. (2020). Barriers and Facilitators That Influence Telemedicine-Based, Real-Time, Online Consultation at Patients' Homes: Systematic Literature Review. Journal of medical Internet research, 22(2), e16407. https://doi.org/10.2196/16407

Archibald, M., Ambagtsheer, R., Casey, M., \& Lawless, M. (2019). Using Zoom Videoconferencing for Qualitative Data Collection: Perceptions and Experiences of Researchers and Participants. In (Vol. 18). International Journal of Qualitative Methods.

Banfield, M., Randall, R., O'Brien, M., Hope, S., Gulliver, A., Forbes, O., Morse, A. R., \& Griffiths, K. (2018). Lived experience researchers partnering with consumers and carers to improve mental health research: Reflections from an Australian initiative. International journal of mental health nursing, 27(4), 12191229. https://doi.org/10.1111/inm.12482

Boivin, A., Richards, T., Forsythe, L., Grégoire, A., L'espérance, A., Abelson, J., \& Carman, K. L. (2018). Evaluating patient and public involvement in research. BMJ, 363. https://doi.org/10.1136/bmj.k5147

Braun, V., \& Clarke, V. (2006). Using thematic analysis in psychology. Qualitative Research in Psychology, 3(2), 77-101. https://doi.org/10.1191/1478088706qp063oa 
Childs, A. W., Unger, A., \& Li, L. (2020). Rapid design and deployment of intensive outpatient, group-based psychiatric care using telehealth during coronavirus disease 2019 (COVID-19). Journal of the American Medical Informatics Association, 27(9), 1420-1424. https://doi.org/10.1093/jamia/ocaa138

Christie, D., \& Viner, R. (2005). Adolescent development. BMJ, 330(7486), 301304. https://doi.org/10.1136/bmj.330.7486.301

Crocker, J., Ricci-Cabello, I., Parker, A., Hirst, J., Chant, A., Petit-Zeman, S., Evans, D., \& Rees, S. (2018). Impact of patient and public involvement on enrolment and retention in clinical trials: systematic review and meta-analysis. British Medical Journal, 363. https://doi.org/10.1136/bmj.k4738

Dandachi, D., Dang, B. N., Lucari, B., Teti, M., \& Giordano, T. P. (2020). Exploring the Attitude of Patients with HIV About Using Telehealth for HIV Care. AIDS patient care and STDs, 34(4), 166-172. https://doi.org/10.1089/apc.2019.0261

Dewa, L. H., Lawrence-Jones, A., Crandell, C., Jaques, J., Pickles, K., Lavelle, M., Pappa, S., \& Aylin, P. (2020). Reflections, impact and recommendations of a co-produced qualitative study with young people who have experience of mental health difficulties. Health expectations : an international journal of public participation in health care and health policy. https://doi.org/10.1111/hex.13088

Fielding, N. G., Lee, R. M., \& Blank, G. (2008). The SAGE Handbook of Online Research Methods. SAGE Publications, Ltd. https://doi.org/10.4135/9781473957992

Hewitt, K. C., Rodgin, S., Loring, D. W., Pritchard, A. E., \& Jacobson, L. A. (2020). Transitioning to telehealth neuropsychology service: Considerations across adult and 
pediatric care settings. Clinical neuropsychologist, 34(7-8), 1335-

1351. https://doi.org/10.1080/13854046.2020.1811891

INVOLVE. (2016). Policy on payment of fees and expenses for members of the public actively involved with INVOLVE. Retrieved December from https://www.invo.org.uk/wp-content/uploads/2016/05/INVOLVE-internalpayment-policy-2016-final-1.pdf

Mawn, L., Welsh, P., Kirkpatrick, L., Webster, L. A. D., \& Stain, H. J. (2016). Getting it right! Enhancing youth involvement in mental health research. Health expectations : an international journal of public participation in health care and health policy, 19(4), 908-919. https://doi.org/10.1111/hex.12386

Medical Research Council. Adolescence, Mental Health and the Developing Mind. Retrieved February 24, 2021. https://mrc.ukri.org/research/initiatives/adolescence-mentalhealth-and-the-developing-mind/

Sellars, E., Pavarini, G., Michelson, D., Creswell, C., \& Fazel, M. (2020). Young people's advisory groups in health research: scoping review and mapping of practices. Archives of Disease in Childhood. https://doi.org/10.1136/archdischild$\underline{2020-320452}$

The Wellcome Trust. Mental health programme strategy. Retrieved February 24, 2021 https://wellcome.org/what-we-do/our-work/mental-health-transforming-research-andtreatments/strategy

United Nations, The 'Convention on the Rights of the Child'. Article 12. (1989). In. 
Webber, L. (2020). Researching with children using Skype interviews and drawings:

Methodological and ethical issues explored. Journal of early childhood research : ECR, 18(4), 339-353. https://doi.org/10.1177/1476718X20938084 